\title{
KEMATANGAN SOSIAL DAN PROBLEM FOCUSED COPING PADA LAKI-LAKI USIA DEWASA AWAL
}

\author{
Qudsi Iftikar Wahyudhi ${ }^{1}$, Tulus Winarsunu ${ }^{2}$, Sofa Amalia ${ }^{3}$ \\ ${ }_{1,2,3}$ Fakultas Psikologi, Universitas Muhammadiyah Malang \\ ${ }^{1}$ Fykar.fykar@gmail.com; ${ }^{2}$ tulus@umm.ac.id; ${ }^{3}$ sofaamalia@umm.ac.id
}

\begin{abstract}
Abstrak. Pada masa dewasa awal yang penuh dengan berbagai perubahan sangat berpotensi menimbulkan berbagai stressor. Dirasa perlu bagi individu untuk memiliki cara penyelesaian masalah yang baik. Salah satunya adalah dengan mengembangkan problem focused coping untuk menyelesaikan sebuah masalah. Pada sisi lain, kematangan sosial diduga dapat mempengaruhi seseorang dalam penggunaan problem focused coping untuk menyelesaikan masalahnya. Tujuan penelitian ini adalah untuk melihat pengaruh kematangan sosial terhadap problem focused coping pada laki-laki usia dewasa awal. Teknik pengambilan sampel menggunakan purposive sampling, dengan melibatkan 121 pekerja, jenis kelamin laki-laki dengan rentang umur 18-25 tahun dan sedang bekerja. Alat ukur yang digunakan dalam penelitian ini adalah skala kematangan sosial dan skala problem focused coping. Data dianalisis menggunakan regresi linear sederhana. Hasil penelitian mengindikasikan ada pengaruh yang signifikan antara kematangan sosial dan problem focused coping pada laki-laki usia dewasa awal yang bekerja di kota Jakarta.
\end{abstract}

Kata kunci: Kematangan sosial, problem focused coping, stress

Abstract. In early adulthood which full of various changes, it has the potential to cause many stressors. A good problem solving skill is needed to overcome the stressor. Problem focused coping is one of the best way to solve a problem. On the other hand, social maturity seemed to affect a person in the use of problem focused coping to solve a problem. The purpose of this research is to find out social maturity's influence towards problem focused coping in early adulthood men. This research uses purposive sampling as the technique of sampling, involving 121 male workers with the age range between 18-25 years old and were working. The measuring instrument used in this research is the scale of social maturity and problem focused coping scale. The data are analysed with simple linear regression. Results of this research showed that there is a significant influence between social maturity and problem focused coping in early adulthood men that works in Jakarta.

Keyword: Social maturity, problem focused coping, stress 
Problem focused coping (PFC) diketahui dapat membantu individu untuk menanggulangi tekanan yang sedang dihadapi. Wijndaele et al., (dalam Van berkel, 2009) menemukan bahwa individu yang menggunakan problem focused coping cenderung berhasil mengurangi stress dan depresi dibanding individu yang menggunakan strategi coping lain. Walker (2014) menemukan bahwa mahasiswa yang menggunakan problem focused coping cenderung berhasil mengurangi dan mengontrol kebiasaan minum alkohol untuk menghindari stress akademik yang dialaminya. Selain itu Problem focused coping terbukti dapat mengembangkan potensi yang dimiliki individu.

Delahaij (2017) menemukan bahwa problem focused coping sangat efektif digunakan dalam pekerjaan yang memiliki resiko tinggi. Problem focused coping menjadikan para pekerja ini memiliki keyakinan akan kemampuan yang mereka miliki dan melihat sebuah tugas yang dapat memicu stress sebagai tantangan yang harus diselesaikan. Veresova et al., (2012) menemukan bahwa problem focused coping memiliki efek yang bagus dalam hal kesehatan tubuh dan juga meningkatkan kemampuan pengaturan kualitas hidup yang lebih baik. Hal ini dikarenakan problem focused coping berorientasi pada masa depan, sumber daya internal yang dimiliki individu yang memungkinkan individu untuk menguatkan tujuan dan rencana hidupnya dan memungkinkan individu untuk memahami masalah sebagai sebuah tantangan yang harus diselesaikan.

Chinaveh (2013) melakukan penelitian terhadap mahasiswa di Iran yang diberikan training mengenai problem focused coping sebagai salah satu metode mengatasi stress, menemukan hasil bahwa problem focused coping secara positif mempengaruhi penyesuaian psikologis.

Dari paparan penelitian diatas, dapat dilihat bahwa Problem focused coping dapat mempengaruhi variabel-variabel lain dan perlu dipelajari dan diaplikasikan pada kehidupan individu dewasa awal. Hurlock (2003) menjelaskan bahwa pada masa dewasa awal terjadi berbagai macam perubahan situasional maupun personal yang dapat menimbulkan stress berlebihan pada diri individu. Salah satu penyebabnya adalah perubahan pola hidup dan transisi peran pada diri individu. Individu dewasa dituntut untuk dapat mendapatkan pekerjaan yang layak dan mengemban tanggung jawab baru seperti menjadi kepala keluarga dan pencari nafkah (Havighurst dalam Mappiare, 1982).

Pada masa dewasa awal individu diharapakan mampu mandiri dalam kehidupan. kondisi perekonomian individu yang tidak bagus, persaingan hidup yang keras ataupun perubahan tidak pasti dalam berbagai aspek kehidupan yang mempersempit kesempatan individu untuk memperoleh kesempatan hidup yang layak dapat berujung pada frustrasi dan stress pada individu.

Santrock (2002) memaparkan bahwa pada masa dewasa awal, individu akan mulai mengatur pemikiran secara operasional dan dituntut untuk dapat bertanggung jawab dalam memutuskan sesuatu sehingga mereka akan membuat hipotesis yang lebih sistematis ketika terpapar oleh masalah dan tidak hanya menggunakan emosi.

Walaupun sudah dinyatakan dalam teori, pada kenyataannya tidak semua individu berhasil menggunakan penyelesaian masalah dengan strategi problem focused coping. Fenomena yang terjadi di kebanyakan negara berkembang seperti Indonesia, penggunaan strategi problem focused coping masih sangat minim. Chang et al., (2014) menemukan bahwa masih banyak pekerja Indonesia yang cenderung menggunakan strategi avoidance 
coping (lari dari permasalahan) dan menggunakan emosi nya (seperti menangis, marah dan perubahan mood) untuk melepaskan beban dalam pikirannya.

WHO (dalam Wirasto, 2012) menyatakan dalam penelitiannya bahwa angka bunuh diri pekerja di kota Jakarta pada pada tahun 2006 mencapai angka 100.000 jiwa. Adapun faktor penyebabnya antara lain adalah kecemasan, keputusasaan, pendapatan rendah dan juga kemiskinan. Dari data tersebut dapat diketahui bahwa masih banyak pekerja di Indonesia yang kurang bisa menanggulangi tekanan yang sedang mereka hadapi, mereka memilih cara-cara yang kurang adaptif untuk menyelesaikan permasalahan yang mereka hadapi tersebut salah satunya dengan melakukan tindakan bunuh diri.

Rumeser et al.,(2011) menemukan dalam penelitiannya pada PT. X di Jakarta bahwa keseluruhan pekerja cenderung menggunakan emosi negatifnya ketika dihadapkan dengan beban tugas yang berat untuk mengurangi stressor kerja tersebut. Para pekerja menganggap sudah tidak ada lagi yang dapat dilakukan terhadap pekerjaan tersebut, sehingga mereka cenderung kurang bisa mengontrol emosinya dalam mengatasi efek stressor tersebut.

Setelah dipaparkan beberapa fenomena di atas, dapat dilihat bahwa penggunaan strategi problem focused coping pada para pekerja dewasa masih sangat minim. Perlu diketahui terdapat beberapa faktor yang mempengaruhi problem focused coping. Menurut Parker (dalam Kertamuda \& Herdiansyah, 2009) problem focused coping dapat muncul pada diri individu dikarenakan beberapa faktor ini; (1) karateristik situasional; (2) Faktor lingkungan dan psikologis; (3) faktor personal atau perbedaan individu yang memungkinkan adanya faktor pengaruh lain seperti jenis kelamin, usia, tingkat pendidikan, status sosial ekonomi, persepsi terhadap stimulus dan tingkat perkembangan kognitif individu.

Mengacu pada pendapat Kertamuda \& Herdiansyah (2009) terdapat faktor perbedaan individu dalam penentuan penggunakan problem focused coping. Hal ini sesuai dengan penelitian Matud (2004) yang menemukan bahwa perbedaan gender dapat menentukan pemilihan strategi coping pada individu. penelitian ini menemukan bahwa wanita cenderung menggunakan emosi ketika menghadapi situasi stress sedangkan pria cenderung menggunakan strategi pemecahan masalah yang mengindikasikan penggunaan problem focused coping untuk mengeliminasi stressor yang ada.

Whittle (2014) dalam penelitianya menemukan bahwa laki-laki dalam penelitiannya menjaga kesehatannya dan juga melakukan tindakan pemecahan masalah terhadap persoalan yang berpengaruh pada moodnya. Subjek laki-laki pada penelitian ini juga menjelaskan bahwa mereka memiliki pandangan bahwa mereka harus dapat menyelesaikan masalahnya dan membantu dirinya agar tidak mengalami stress/depresi yang berkepanjangan.

Beberapa penelitian juga menemukan bahwa beberapa laki-laki mengekspresikan/ menanggulangi permasalahanya dalam bentuk yang sama sekali tidak membantu, tidak pantas dan tidak tepat (Hoy, 2012; Nolen, 2001). Laki-laki dapat mengekspresikan stress nya dalam bentuk amarah, menarik diri, agresi, pengambilan resiko, dan perilaku lainnya yang tidak berorientasi pada penyelesaian masalah seperti mengkonsumsi alkohol, bekerja berlebihan dan menyakiti diri sendiri (Brownhill, Wilhelm, Barclay, \& Parker, 2002; Brownhill, Wilhelm, Barclay, \& Parker 2005; Danielsson \& Johansson, 2005). 
Farzana et al, (2015) dalam penelitiannya pada 374 pengajar laki-laki menyatakan bahwa para subjek memiliki goal setting dan mencari dukungan emosional dalam menyelesaikan permasalahannya. Dari paparan fenomena diatas, gender dapat mempengaruhi penggunaan strategi coping dan laki-laki akan cenderung menyelesaikan permasalahannya dengan menyusun strategi penyelesaian, mencari informasi, dukungan dan lain sebagainya yang merupakan aspek dari problem focused coping. Namun masih belum ada penelitian yang secara jelas menjelaskan karakteristik laki-laki seperti apa yang cenderung menggunakan problem focused coping sebagai cara untuk menanggulangi stress, maka dalam penelitian ini diajukan gagasan bahwa kematangan sosial dapat mempengaruhi problem focused coping pada laki-laki.

Goleman (2007) menjelaskan bahwa kematangan sosial adalah kemampuan untuk mengerti orang lain dan bereaksi pada situasi sosial yang berubah ubah. Rosenberg (dalam Singh \& Thukral, 2010) menjelaskan bahwa kematangan sosial dapat memfasilitasi individu untuk mengembangkan perilaku lebih pantas dan sesuai dengan keadaan sehingga akan berpengaruh pada penggunaan problem focused coping pada individu. Porvaznik (2014) menambahkan, bahwa individu dengan kematangan sosial yang baik cenderung berhasil untuk mengatasi berbagai macam masalah dengan baik. Mereka mampu meregulasi emosinya dan memiliki kemampuan untuk berfikir panjang sebelum membuat sebuah tindakan. Individu yang matang secara sosial akan dapat mengembangkan problem focused coping karena memiliki pemahaman tentang karakteristik sumber masalah dan bagaimana harus mengatasinya.

Singh et al., (2010) menemukan bahwa kematangan sosial dapat dipengaruhi oleh faktor kepribadian yang terbuka, kedekatan dengan linkungan, kepekaan pada keadaan dan kepedulian individu terhadap sesama. Singh (2010) menambahkan bahwa kematangan sosial dapat menjadi ukuran kompetensi perkembangan individu karena adanya faktor seperti hubungan interpersonal, perilaku yang sesuai, pemecahan masalah sosial dan penilaian sosial. Menurut Rosenberg (dalam Singh \& Thukral, 2010) faktor-faktor tersebut mengarahkan individu pada kemandirian, komunikasi interpersonal yang efektif, kemampuan berinteraksi dan kemampuan bertanggung jawab.

Penelitian ini bertujuan untuk menilik pengaruh kematangan sosial terhadap problem focused coping pada laki-laki. Diharapkan dengan adanya penelitian ini mampu menambahkan referensi penelitian psikologi terkait pentingnya memiliki problem focused coping dan kematangan sosial bagi individu laki-laki di masa dewasa awal. Selain itu, penelitian ini diharapkan dapat memberikan pemahaman bagi individu pada masa dewasa awal maupun yang akan memasuki masa dewasa awal, diharapkan dengan adanya penelitian ini pembaca dapat memahami pentingnya memiliki kematangan sosial dan penyelesaian masalah yang baik agar dapat terhindar dari stressor.

\section{METODE}

Penelitian ini menggunakan pendekatan kuantitatif. Creswell (2014) menyatakan penelitian kuantitatif merupakan pendekatan untuk menguji teori objektif dengan menguji hubungan antar variabel. Adapun desain penelitian yang digunakan pada penelitian ini adalah desain penelitian ex post facto, yang digunakan tanpa memanipulasi variabel bebas dan bersifat deskriptif dan juga eksploratif (Sarwono, 2006). Pada 
penelitian ini, terdapat 2 variabel yang akan diteliti, kedua variabel ini adalah problem focused coping sebagai variabel terikat $(\mathrm{Y})$ dan kematangan sosial sebagai variabel bebas (X).

Subjek yang digunakan pada penelitian ini adalah 121 laki-laki pada masa dewasa awal yang bekerja diberbagai perusahaan swasta maupun negeri di kota Jakarta. Adapun pemilihan karakteristik subjek ini didasarkan pada teori dewasa awal yang dikemukakan oleh Hurlock yang menyatakan bahwa pada masa dewasa awal individu akan menerima peran, tanggung jawab dan harapan baru yang diberikan oleh lingkungan sekitar individu (Hurlock, 2003). Pengambilan subjek pada penelitian ini menggunakan teknik sampling purposive sampling. Adapun kriteria calon subjek pada penelitian ini adalah sebagai berikut: (1) Berjenis kelamin laki-laki; (2) Berada pada masa dewasa awal; (3) Sedang bekerja; (4) Berdomisili di kota Jakarta.

Problem focused coping adalah salah satu strategi coping yang berorientasi untuk mengeliminasi stressor atau merubah situasi yang menimbulkan stress sehingga tidak lagi memiliki efek berkepanjangan pada diri individu. Skala yang digunakan untuk mengukur problem focused coping pada individu, peneliti mengadaptasi skala coping stress yang dibuat oleh Carver et al., (1989). Skala ini memiliki 5 indikator problem focused coping dengan jumlah aitem pertanyaan sebanyak 20 butir. Skala ini diukur dengan cara mengkategorikan pilihan jawaban calon subjek. Jawaban harus sesuai dengan keadaan diri subjek dan tidak membandingkan jawaban subjek dengan "apa yang kebanyakan orang lakukan pada situasi tersebut". Kategori jawaban tersebut di bagi menjadi ; "saya biasanya tidak menggunakan hal tersebut sama sekali", "saya biasanya sedikit melakukan hal tersebut", "saya ragu tentang hal tersebut", "saya biasanya melakukan hal tersebut", "saya biasanya sering melakukan hal tersebut". Untuk melakukan skoring, kategori jawaban diurutkan dari 1-5. Adapun indeks validitas ( $\mathrm{r}$ hitung) dari skala ini setelah di uji cobakan pada 66 responden berada pada rentang 0,417-0,811 dengan $r$ table sebesar 0,244 . Sedangkan indeks relibilitas pada skala ini adalah sebesar 0,944 dengan jumlah total item yang valid sebanyak 20 item. Adapun contoh item pada variabel ini adalah sebagai berikut : Saya melakukan sesuatu untuk menyelesaikan masalah saya.

Sedangkan kematangan sosial yang dimaksud dalam penelitian ini, merupakan penilaian laki-laki dewasa awal terkait dengan kemampuannya dalam menyesuaikan dirinya agar dapat diterima di lingkungannya dengan mengembangkan perilaku perilaku yang sesuai dengan tempat dimana individu berada. Skala kematangan sosial yang digunakan pada penelitian ini adalah skala kematangan Sosial yang dikemukakan oleh Dr. Nalini Rao yang dinamakan Rao's Social Maturity Scale (dalam Srilatha, 2012). Skala ini memiliki 90 item yang dibagi dalam 3 kategori yaitu; Interpersonal adequacy, personal adequacy dan social adequacy. Dari 90 item ini, ada 23 item yang berorientasi positif dan 67 yang berorientasi negatif. Dalam kategori pertama (personal adequacy) hanya ada 1 item, dalam interpersonal adequacy ada 9 item yang berorientasi positif dan di kategori social adequacy ada 13 item yang berorientasi positif dan sisa 67 dari ketiga item berorientasi negatif. Semua item skala berbentuk pertanyaan dengan bentuk jawaban : sangat setuju, setuju, tidak setuju, sangat tidak setuju. Setiap jawaban pada pertanyaan yang berorientasi positif "sangat setuju" akan diberikan skor 5, "setuju" diberikan 4, "netral" akan diberikan skor 3 "tidak setuju" akan diberikan 2 dan "sangat tidak setuju" diberikan skor 1. Sebaliknya, pertanyaan yang berorientasi negative akan mendapat skor sebaliknya. Adapun indeks validitas ( $\mathrm{r}$ hitung) dari skala ini setelah di uji cobakan pada 
66 responden berada pada rentang 0,245-0,635 dengan $r$ table sebesar 0,244. Sedangkan indeks relibilitas pada skala ini adalah sebesar 0,941 dengan jumlah total item yang valid sebanyak 75 item. Adapun contoh item pada variabel ini adalah sebagai berikut : Saya sangat sulit untuk bertahan pada suatu hal yang membutuhkan waktu yang sangat lama untuk dikerjakan

\section{HASIL}

Penelitian ini dilakukan untuk melihat pengaruh dari kematangan sosial terhadap problem Focused Coping pada laki-laki usia dewasa awal yang sedang bekerja di kota Jakarta. Sebanyak 121 responden dari yang bekerja diberbagai macam perusahaan di kota Jakarta telah mengisi kuisioner penelitian ini

Uji normalitas digunakan untuk menentukan distribusi dari data variabel yang ada. Uji normalitas bertujuan untuk menguji apakah dalam model regresi, variabel pengganggu atau residual memiliki distribusi data yang normal atau penyebaran data statistik pada sumbu diagonal dari grafik berdistribusi normal. Data yang baik haruslah berdistribusi normal. Uji normalitas dilakukan dengan tes Kolmogorov-Smirnov melalui program SPSS. Berikut adalah table uji normalitas dengan tes Kolmogorov-Smirnov dengan 95\% derajat kepercayaan atau $\alpha=0,05(5 \%)$.

Berdasarkan data penelitian yang sudah diolah, didapatkan hasil bahwa nilai signifikansi (Asymp. Sig. 2-tailed) sebesar .092. karena nilai signifikansi lebih dari 0,05 maka nilai residual terdistribusi normal.

Tabel 1. Hasil Kategorisasi Kematangan Sosial

\begin{tabular}{lccc}
\hline Klasifikasi & Rentang skor & Frekuensi & Presentase \\
\hline Tinggi & $49,86-78,99$ & 63 & $52,06 \%$ \\
Rendah & $7,90-49,86$ & 58 & $47,94 \%$ \\
\hline Total & & 121 & $100 \%$ \\
\hline
\end{tabular}

Dari tabel 1. diatas, dapat diketahui bahwa dari 121 subjek telah diklasifikasikan menjadi 2 kategori yakni tinggi dan rendah. Hasil dari kategori kematangan sosial yang tinggi sebanyak 63 orang, hasil dari kategori rendah sebanyak 58 orang. Dari table tersebut menunjukan bahwa 52,06\% dari keseluruhan subjek memiliki kematangan sosial yang tinggi.

Tabel 2. Hasil Kategorisasi Problem Focused Coping

\begin{tabular}{lccc}
\hline Klasifikasi & Rentang skor & Frekuensi & Presentase \\
\hline Tinggi & $51,99-68,21$ & 63 & $52,06 \%$ \\
Rendah & $16,06-51,99$ & 58 & $47,94 \%$ \\
\hline Total & & 121 & $100 \%$ \\
\hline
\end{tabular}

Dari tabel 2 diatas, dapat diketahui bahwa dari 121 subjek telah diklasifikasikan menjadi 2 kategori yakni tinggi dan rendah. Hasil dari kategori kematangan sosial yang tinggi sebanyak 63 orang, hasil dari kategori rendah sebanyak 58 orang. Dari table tersebut 
menunjukan bahwa 52,06\% dari keseluruhan subjek memiliki problem focused coping yang tinggi

Tahapan selanjutnya adalah melihat uji hipotesis pada penelitian ini. Pengujian hipotesis merupakan bagian penting dalam penelitian, setelah data terkumpul dan diolah. Kegunaan utamanya adalah untuk menjawab hipotesis yang dibuat oleh peneliti. Pengujian $\mathrm{F}$ atau pengujian model digunakan untuk mengetahui apakah hasil dari analisis regresi signifikan atau tidak, dengan kata lain model yang diduga tepat/sesuai atau tidak. Jika hasilnya signfikan, maka $\mathrm{H}_{0}$ ditolak dan $\mathrm{H}_{1}$ diterima. Sedangkan jika hasilnya tidak signifikan, maka $\mathrm{H}_{0}$ diterima dan $\mathrm{H}_{1}$ ditolak. Berikut adalah Uji $\mathrm{F}$ yang digunakan untuk menjawab hipotesis pada penelitian ini :

Tabel 3. Hasil Uji F

\begin{tabular}{cccccc}
\hline Model & $\begin{array}{c}\text { Sum Of } \\
\text { Squares }\end{array}$ & df & $\begin{array}{c}\text { Mean } \\
\text { Square }\end{array}$ & F & Sig. \\
\hline Regression & 11099.571 & 1 & 11099.571 & 101.128 & .000 \\
Residual & 13061.123 & 119 & 109.75711 & & \\
Total & 24160.694 & 120 & & & \\
\hline
\end{tabular}

Berdasarkan Tabel 3, nilai F hitung sebesar 101.128. Sedangkan F tabel $(\alpha=0.05 ; \mathrm{db}$ regresi $=1: \mathrm{db}$ residual $=119)$ adalah sebesar 3,921. Karena $\mathrm{F}$ hitung $>\mathrm{F}$ tabel yaitu $101,128>3,921$ atau nilai sig $\mathrm{F}(0,000)<\alpha=0.05$ maka model analisis regresi adalah signifikan. Hal ini berarti $\mathrm{H}_{0}$ ditolak dan $\mathrm{H}_{1}$ diterima sehingga dapat disimpulkan bahwa problem focused coping (Variabel Terikat) dapat dipengaruhi secara signifikan oleh kematangan sosial (Variabel Bebas)

Untuk mengetahui besar kontribusi variabel bebas (Kematangan sosial) terhadap variabel terikat (problem focused coping) digunakan nilai $\mathrm{R}^{2}$, nilai $\mathrm{R}^{2}$ seperti dalam Tabel 4 dibawah ini:

Table 4. Hasil Uji Analisis Statistik Koefisien

\begin{tabular}{llll}
\hline Model & $\mathrm{R}$ & $\mathrm{R}$ Square & Sig. \\
\hline 1 & 0,678 & 0,459 & 0,000 \\
\hline
\end{tabular}

Berdasarkan tabel 4, untuk mengetahui besarnya korelasi/ hubungan (R) yaitu sebesar 0,678. Diketahui juga bahwa ( $\mathrm{R}$ Square) sebesar 0,459, yang menandakan adanya pengaruh variable bebas (kematangan sosial) terhadap variable terikat (Problem Focused Coping) sebesar 45,9 \% dari kemungkinan $100 \%$ dan dapat diketahui pula bahwa kepuasan pernikahan dipengaruhi variable lain sebesar $54,1 \%$.

Persamaan regresi digunakan mengetahui bentuk hubungan antara variabel bebas (kematangan sosial) dengan variabel terikat (problem focused coping). Sehingga didapatkan model regresi seperti pada Tabel 5

Tabel 5. Hasil Persamaan Regresi

\begin{tabular}{lcccc}
\hline Model & B & Beta & t & Sig. \\
\hline (Constant) & 8,948 & 0,678 & 1,365 & 0,175
\end{tabular}


$\begin{array}{llll}\text { Kematangan } & 0,252 & 10,056 & .000\end{array}$

Sosial

Berdasarkan tabel 6 didapatkan persamaan regresi sebagai berikut :

$$
\mathrm{Y}=8,948+0,252 \mathrm{X}
$$

Dari persamaan diatas dapat di interpretasikan yakni konstanta sebesar 8,948, menunjukkan bahwa rata - rata variabel terikat (Problem Focused Coping) jika tidak ada variabel bebas (Kematangan Sosial) adalah sebesar 8,948. Variabel terikat akan meningkat sebesar 0,252 satuan untuk setiap tambahan satu satuan $X_{1}$ (Variabel Bebas). Jadi apabila variabel bebas mengalami peningkatan 1 satuan, maka variabel terikat akan meningkat sebesar 0,252 satuan dengan asumsi variabel yang lainnya dianggap konstan.

Dari hasil keseluruhan dapat disimpulkan bahwa kematangan sosial mempunyai pengaruh yang signifikan terhadap problem focused coping. Dan dari hasil ini dapat diketahui bahwa variabel bebas tersebut memberikan pengaruh yang tinggi terhadap variabel Terikat.

\section{DISKUSI}

Berdasarkan hasil regresi linear sederhana, uji hipotesis dapat dilihat bahwa ada pengaruh yang signifikan dari kematangan sosial terhadap problem focused coping pada laki-laki di usia dewasa awal. Semakin tinggi kematangan sosial seseorang maka akan semakin tinggi pula problem focused coping orang tersebut. Begitupun sebaliknya, semakin rendah kematangan sosial seseorang maka akan semakin rendah pula problem focused coping orang tersebut. Adapun presentasi kematangan sosial mempengaruhi problem focused coping yaitu sebesar $45,9 \%$ dan $45,1 \%$ dipengaruhi oleh faktor lain-lain. Faktor lain-lain yang dimaksud dapat berupa faktor genetis, lingkungan, pola asuh, status sosial dan ekonomi (Matsubara, 1964; Srilatha, 2012).

Penelitian ini menggunakan responden laki-laki pada masa dewasa awal yang berusia 18 hingga 25 tahun. Masa perkembangan ini dipilih karena pada masa-masa ini adalah yang sulit bagi para laki-laki karena banyaknya tekanan baru yang harus diterima dan dapat menyebabkan stress. Sumber stress tersebut antara lain peran baru, tugas dan tanggung jawab yang harus diterima seperti menjadi kepala keluarga, mulai memiliki karir yang baik dan juga menjadi pemimpin bagi keluarganya (Hurlock, 2003). Dengan memiliki problem focused coping yang baik, individu dapat mengeliminasi stressornya dan mengembangkan pola pikir solutif dalam menyelesaikan sebuah masalah.

Menurut Lazarus dan Folkman (1984) individu yang memiliki problem focused coping yang baik haruslah memiliki keterampilan sosial yang baik untuk dapat menganalisis situasi dan beradaptasi dalam lingkungan tertentu. Hal ini dapat membantu individu dalam mencari dukungan sosial yang juga merupakan salah satu aspek dari problem focused coping. Selain itu, individu yang memiliki problem focused coping yang bagus akan dapat menyusun rencana untuk menyelesaikan suatu masalah.

Hasil penelitian ini juga mengindikasikan bahwa kematangan sosial pada individu secara signifikan berpengaruh pada pemilihan problem focused coping sebagai cara 
menyelesaikan masalah pada responden penilitian. Hal ini terlihat dari hasil kategorisasi kedua variabel yang menunjukan angka yang tinggi, dengan rincian pada variabel kematangan sosial sebanyak 63 orang yang berada pada kategori tinggi dan pada variabel problem focused coping sebanyak 63 orang atau lebih dari setengah responden. Hal ini sesuai dengan pendapat Hurlock (2003) yang menjelaskan bahwa individu yang matang secara sosial memiliki pemahaman diri yang baik, lebih berhasil dalam menjalani reaksi dengan lingkungannya dan cenderung sangat hati-hati dalam bertindak dan menyelesaikan sebuah permasalahan.

Hasil penelitian ini juga mendukung pendapat Porvaznik (2014) yang menyatakan bahwa individu dengan kematangan sosial yang baik dapat menyelesaikan masalahnya dengan baik karena mereka mampu berfikir panjang, mau memikirkan orang lain dan memiliki regulasi emosi yang baik. Selain itu, adanya pengaruh yang signifikan juga dipengaruhi oleh kesinambungan aspek yang dimiliki kedua variabel. Carver dan Scheier (1989) menyatakan bahwa salah satu aspek dari problem focused coping adalah restraint coping, yaitu menahan diri untuk tidak bertindak gegabah. Hal ini juga dijelaskan oleh Nalini (2002) dalam indikator individu yang matang secara sosial. Salah satu yang mengindikasikan individu matang secara sosial adalah kemampuan individu untuk mengatasi stress. Menurut Nalini, individu yang matang secara sosial akan mampu menganalisis sebuah masalah dan tidak bertindak gegabah dalam menyelesaikan permasalahannya.

Walaupun telah disimpulkan bahwa kematangan sosial memiliki pengaruh terhadap problem focused coping pada laki-laki usia dewasa awal yang bekerja di kota Jakarta, akan tetapi kematangan sosial bukan sepenuhnya variabel yang mempengaruhi problem focused coping. Artinya, problem focused coping yang timbul pada diri individu tidak hanya disebabkan oleh kematangan sosial yang dimiliki. Hal ini dapat terlihat dari persentase kematangan sosial yang berada pada angka 45,9 \% maka dapat disimpulkan bahwa masih ada $45,1 \%$ faktor lain yang tidak diteliti yang dapat mempengaruhi problem focused coping pada laki-laki usia dewasa awal.

Faktor lainnya yang dapat mempengaruhi problem focused coping menurut Parker (1986) antara lain : karakteristik situasional, faktor lingkungan dan psikologis dan juga faktor personal atau perbedaan individu. Dengan adanya faktor-faktor lain ini, sangat mungkin setiap individu memiliki tingkat problem focused coping yang berbeda beda juga. 


\section{SIMPULAN DAN IMPLIKASI}

Dilihat dari hasil penelitian yang terdapat pengaruh yang signifikan antara variabel kematangan sosial dan problem focused coping pada laki-laki masa dewasa awal yang bekerja di kota Jakarta. Dengan melihat hasil dari penelitian ini, diharapkan pada lakilaki usia dewasa awal lebih memahami lagi pentingnya peran problem focused coping dalam mengeliminasi stressor yang akan terus datang dalam hidup. Karena dengan menggunakan penyelesai masalah yang efektif, permasalahan akan hilang dan tidak menjadi beban pikiran lagi.

Perlu diperhatikan juga bahwa memiliki kematangan sosial yang baik akan membantu individu dalam menghadapi permasalahan sosial maupun pribadi. Sehingga dengan begitu diharapkan mampu menekan stress pada kehidupan individu di masa dewasa awal yang penuh dengan peran-peran baru, tanggung jawab baru, ekspektasi sekitar maupun krisis idealisme yang sangat berpotensi memicu stress pada kehidupan individu laki-laki di usia dewasa awal. Untuk melatih kemampuan strategi problem focused coping yang baik, bisa dilakukan dengan cara membiasakan berfikir positif, bersikap tenang, menerima diri sendiri, pelajari kesalahan, objektif, jalin hubungan baik dengan orang lain dan bangun pengendalian diri dengan disiplin.

Diharapkan pada peneliti selanjutnya dapat mengkaji faktor-faktor lain yang mempengaruhi problem focused coping yang tidak terbahas pada penelitian ini. Keterbatasan skala untuk mengukur kematangan sosial menjadi salah satu kesulitan pada penelitian ini. Maka dari itu diharapkan pada peneliti selanjutnya agar dapat menemukan skala baru untuk mengukur kematangan sosial pada individu usia dewasa awal.

\section{REFERENSI}

Amemiya, J., \& Wang, M. Te. (2018). African American adolescents' gender and perceived school climate moderate how academic coping relates to achievement. Journal of School Psychology, 69(January), 127-142.

Baker, J. P., \& Berenbaum, H. (2007). Emotional approach and problem-focused coping : A comparison of potentially adaptive strategies. Congintion and Emotion, 21(1), $37-41$.

Bibi, F., Kazmi, S. F., Chaudhry, A. G., \& Awan, E. A. (2015). Coping strategies among male and female university teachers of coping strategies among male and female university. International Journal of Antrophology, 27(1), 727-730.

Brownhill, S., Wilhelm, K., Barclay, L., \& Parker, G. (2002). Detecting depression in men: a matter of guesswork. International Journal Of Men's Health., 1, 259-389.

Brownhill, S., Wilhelm, K., Barclay, L., \& V, S. (2005). Big build: hidden depression in men. Australian and Newzealand Journal Of Psychiatry, 39(31), 921.

Carver, C. S., \& Scheier, M. F. (1989). Assessing coping strategies : a theoretically based approach, 56(2), 267-283. 
Chang, K., \& Taylor, J. (2014). Do your employees use the right coping strategy? International Journal of Commerce and Strategy, 5(2), 099-116.

Chaplin, J. P. (2000). Kamus lengkap psikologi. Jakarta: Rajawali.

Chinaveh, M. (2013). The Effectiveness of problem-solving on coping skills and psychological adjustment. Procedia - Social and Behavioral Sciences, 84, 4-9.

Creswell, J. W. (2014). Research design: qualitative, quantitative and mixed methods approaches (4th ed.). London: Sage.

Danielsson, U., \& Johansson, E. (2005). Beyond weeping and crying : a gender analysis of expression of depression. Scandinavian Journal of Primary Health Care, 23(1), 171.

Dariyo, A. (2003). Psikologi perkembangan dewasa muda. Jakarta: PT. Gramedia Widiarsana.

Delahaij, R., \& Van Dam, K. (2017). Coping with acute stress in the military: The influence of coping style, coping self-efficacy and appraisal emotions. Personality and Individual Differences, 119, 13-18.

Doll, F. . (1965). Vineland social maturity scale. Minnesota: American Guidance Service.

Goleman, D. (2007). Social intelligence: the new science of human relationship. London: Arrow.

Hoy, S. (2012). Beyond men behaving badly: A meta-etnography of men's perspective on psychological distress and help seeking. International Journal Of Men's Health., $11,202$.

Hurlock, E. B. (2003). Psikologi perkembangan; suatu perkembangan sepanjang rentang kehidupan. (R. M. Sijabat, Ed.) (5th ed.). Erlangga.

Kovrygin, S. ., \& Kazantseva, D. . (2013). Social and moral maturity of the modern society. Penza, Russia.

Labouvie-vief, G. (1986). Intelligence and cognition. New York: Von Nostrand Reinhold. Co.

Lazarus, R. . (1984). Stress appraisal and coping. New York: Springer Publishing Company.Inc.

Mappiare, A. (1982). Psikologi remaja. Surabaya: Usaha Nasional.

Matsubara, T. (1964). The development and effective factors in social maturity of children. Journal of Education, 12(3), 152-165.

Matud, M. P. (2004). Gender differences in stress and coping styles. Personality and Individual Differences, 37(7), 1401-1415.

Moradi, A., Pishva, N., Bahrami, H., \& Hadadi, P. (2011). The relationship between 
coping strategies and emotional intelligence. Social And Sciences, 30, 748-751.

N. Glozah, F. (2013). Effects of academic stress and perceived social support on the psychological wellbeing of adolescents in Ghana. Open Journal of Medical Psychology, 02(04), 143-150.

Navas González, F. J., Jordana Vidal, J., León Jurado, J. M., Arando Arbulu, A., McLean, A. K., \& Delgado Bermejo, J. V. (2018). Genetic parameter and breeding value estimation of donkeys' problem-focused coping styles. Behavioural Processes, 153(May), 66-76.

Nolen, H. (2001). Gender differences in depression ; current direction in psychological science. Clinical Psychology, 10(173), 6.

Parker, K. . (1986). Coping in stressful episodes : the role of individual differences, environmental factor and situasional charateristic. Journal of Personality and Social Psychology, 51(6), 1277-1292.

Perry, W. G. (1999). Forms of ethical and intellectual development in the college years. San Francisco: Jossey-Bass Publisher.

Persike, M., \& Seiffge-Krenke, I. (2016). Stress with parents and peers: how adolescents from 18 nations cope with relationship stress. Anxiety, Stress and Coping, 29(1), 38-59. https://doi.org/10.1080/10615806.2015.1021249

Porvaznik, J., \& Misun, J. (2014). Importance and role of social maturity in the concept of holistic managerial competence. (No. 54287). Bratislava.

Rao, N. (2002). Manual for rao's maturity scale. Bangalore: Agra Publication.

Rumeser, J. A. A., \& Tambuwun, T. E. (2011). Hubungan antara tingkat stres kerja dengan pemilihan coping stress strategy karyawan di kantor pusat adira insurance. Psychology, 2(1), 214-227.

Santrock. (2003). Adolescence : Perkembangan remaja (6th ed.). Jakarta: Erlangga.

Santrock, J. . (2002). Life span development : perkembangan masa hidup jilid 2 (5th ed.). Jakarta: Erlangga.

Sarwono, J. (2006). Metode penelitian kuantitatif. Yogyakarta: Graha Ilmu.

Shabeena, P., Shawl, I., \& Mehraj, N. (2017). Impact of academic stress : a study of coping strategies among adolescents, 22(12), 40-45.

Sharma, N., Sharma, S., \& Kang, T. K. (2017). Assessment of social and emotional maturity in juvenile delinquents. Journal Of Positive Psychology, 8(4), 4937.

Shimazu, A., \& Schaufeli, Æ. W. B. (2007). Does distraction facilitate problem-focused coping with job stress ? a 1 year longitudinal study, 423-434.

Singh, S., \& Thukral, P. (2010). Social maturity and academic achievement of high school students, 1(1), 6-11. 
Smet, B. (1994). Psikologi kesehatan. Jakarta: Grasindo.

Srilatha, B. (2012). Emotional maturity, social maturity and moral judgement of the student teacher of guntur district. Acharya Nagarjuna University.

Tripathy, M. (2017). The comparative study of social maturity among yog students of master degree. International Journal of Advance Research, Ideas and Innovations in Technology., 3(6), 1285-1291.

Van berkel, H. (2009). The relationship between personality, coping styles and stress, anxiety and depression. University of Canterbury.

Verešová, M., \& Malá, D. (2012). Stress, Proactive coping and self- efficacy of teachers. Procedia - Social and Behavioral Sciences, 55(2001), 294-300. https://doi.org/10.1016/j.sbspro.2012.09.506

Walker, R., \& Stephens, R. S. (2014). Protective behavioral strategies mediate problemfocused coping and alcohol use in college students. Addictive Behaviors, 39(6), 1033-1037.

Whittle, E., Fogarty, A., Player, M., \& Whitton, A. (2014). Doing what comes naturally: positive self help strategies used by men to prevent depression and suicide. Sidney.

Wirasto, R. T. (2012). Suicide prevention in Indonesia: Providing public advocacy, 55(1), 98-104. 